\title{
Aproximación a la conyuntura actual de la música en el departamento del Huila
}

\author{
LIBERIO SALAZAR TRUJILLO*
}

$\mathrm{H}$

ay consenso entre los huilenses en que una de las características que constituyen su identidad e integran su idiosincracia es la inclinación por la música. Y si bien son muchas las regiones, (por no decir todas las de nuestro país), que se atribuyen cualidad similar, (entre ellas nuestra región hermana con la que conformamos el Tolima Grande), es válido comparar la dinámica de nuestro desarrollo musical con la suya para tomarle el pulso a la coyuntura actual de la música en nuestro departamento. Examinemos entonces, (con ánimo de polemizar y abrir la discusión para conocer la realidad), los elementos que la conforman, con miras a poner las soluciones oportunas y adecuadas de cara a dar un nuevo impulso y brío a este hermoso arte en nuestro entorno regional y a determinar el papel y la función que la universidad puede y debe ejercer en esa dirección.
Partimos de la hipótesis de que aunque no pueda hablarse apropiadamente de retroceso, sí se observan indicios de estancamiento en relación con otras épocas y con otras regiones.

En el campo de la música folclórica y desde el horizonte de la producción, el país reconoce nuestro aporte al repertorio nacional, con un número considerable de canciones de apreciable valor. Un compositor huilense, el doctor Villamil Cordovez se ubica al lado de Morales en Santander, Vieco en Antioquia, Bermudez, Barros y Escalona en la región Atlántica, como los más destacados y reconocidos talentos de la música autóctona, en referencia, claro está a los nacidos en este siglo. Pero es necesario colocar al lado de Villamil un considerable número de autores de notable inspiración que alcanzarían a trascender las fronteras regionales, si contaran con un apoyo más decidido 
UnIVERSIDAd SURCOLOMBIANA

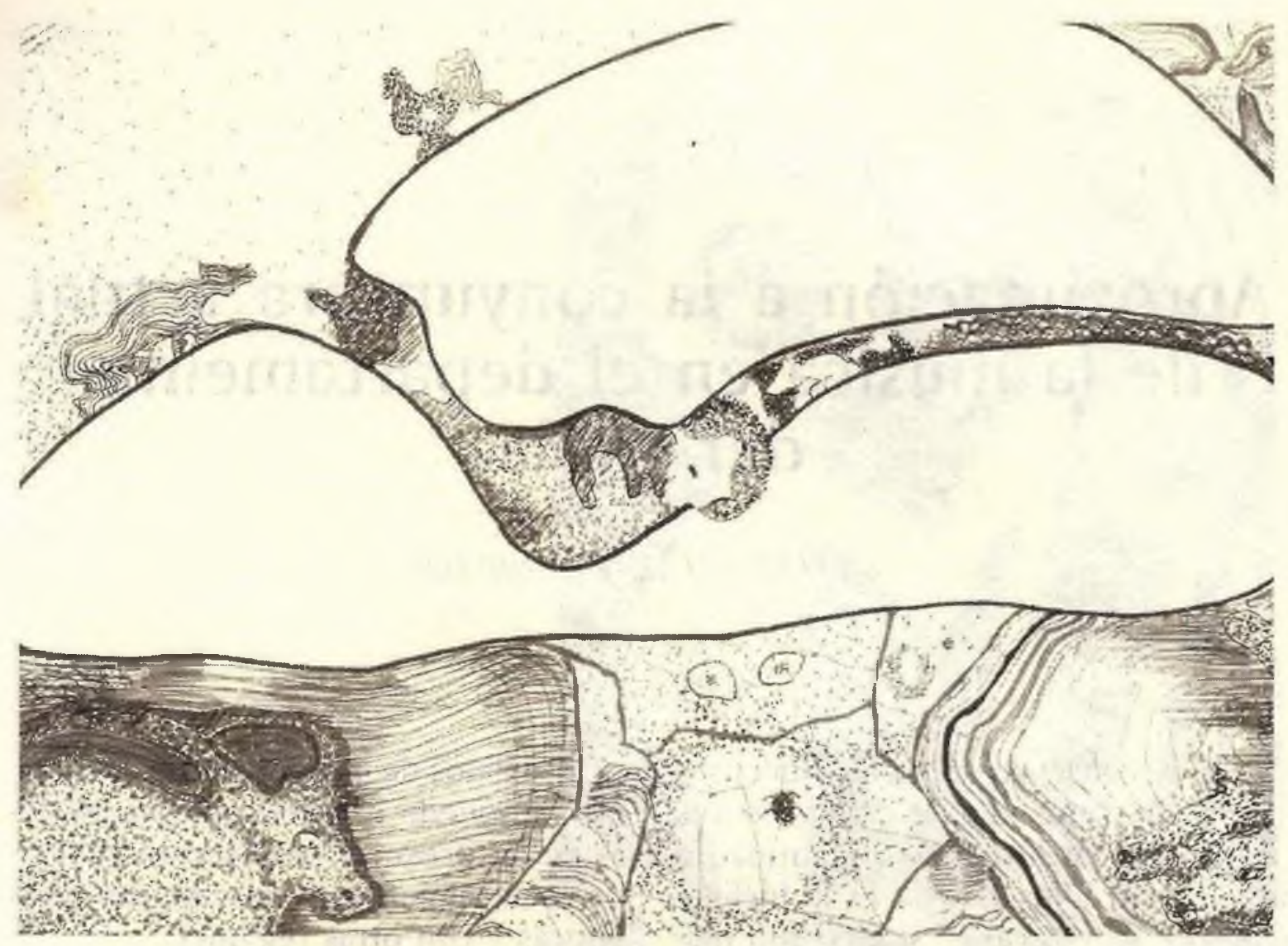

Ilustración: Luis Fernando Bernal

por parte de políticas y criterios oficiales. Cabe destacar a los egresados del Programa de la Universidad Surcolombiana que han hecho un aporte de renovación y técnica musical al arte de la composición, alcanzando puestos de consideración en los concursos nacionales; y a compositores como Luciano Díaz o Guillermo Calderón, que se han alejado de los cánones tradicionales buscando un estilo diferente al implantado en los últimos años. En el campo de la música erudita merece mención especial la obra del sacerdote salesiano Andrés Rosa Summa, inexplorada e inédita todavía, casi en su totalidad. Sobra agregar que, fuera de Villamil, ningún compositor huilense vive de su producción; es más, muchos no solo logran retribución económica por su obra sino que deben invertir parte de lo que obtienen a través de otras fuen- tes, para alcanzar la publicación y divulgación de su música, a pesar de existir de nombre un ente llamado Fondo Mixto de Promoción de las Artes, que debería cumplir esa función.

Pasando al campo de la interpretación, sería oportuno realizar a través de procesos serios de investigación, el registro de conjuntos, asociaciones, grupos, duetos, solistas que practican la música por profesión y/o por afición el dueto Silva y Villalba ocupa hoy en el reconocimiento nacional el lugar del desaparecido Garzón y Collazos entre las decenas de agrupaciones similares. $Y$ en nuestro ámbito regional lo va adquiriendo el dueto Ensueños. Vocalistas e instrumentistas jóvenes han ganado primeros lugares en los festivales musicales más acreditados, realizados en distintos escenarios. 
Los aires folclóricos exclusivamente nuestros, son dos modalidades del bambuco: el sanjuanero y el rajaleña. El segundo se mantiene todavía circunscrito al departamento $y$, a nuestro modo de ver, empieza a superar al anquilosamiento que lo afectó durante más de 20 años. El primero ha logrado mayor penetración y aceptación, pero nunca en la proporción en que los aires vallenatos, por ejemplo, han invadido o más bien tomado por asalto, el ámbito musical nacional en los últimos 20 años. Imposible dejar de reconocer que la región vallenata (esto es, sus gentes y sus autoridades) tomó como propósito defender, impulsar, apoyar y respaldar económica, política y culturalmente sus aires vernáculos como es imposible dejar de mencionar que otros países defienden el trabajo de sus músicos profesionales, (México, valga el caso), mediante leyes restrictivas de todo lo que desmejore las condiciones de ejercicio y de vida de Los cultivadores de sus tradiciones folclóricas músicales. Y lo anterior hace relación a la representatividad que del artista en general y de la música en particular se ha hecho en nuestro departamento. Frente a la actitud insular y resignada del músico por decisión personal y del opita por su tradición, ha hecho aparición en el Huila un grupúsculo que se arrogó la vocería y representación de los artistas, zanahorizándolos con el proyecto de un Movimiento Cultural a base de manipulación y componendas políticas se apoderó de los puestos directivos de la Cultura en el Departamento y el Municipio, y se repartió el presupuesto de los Fondos Mixtos de Promoción de la misma, que se le confiaron, según consta en acta, hasta el año 2.010. A pesar de las denuncias del gobernador Losada y de muchos conocedores del asunto, ha contado con el apoyo ciego del anterior Ministro de Cultura y de algunos políticos huilenses a los cuales ha aportado votos en las elecciones, y mantiene por tanto, su estructura de poder. Es de esperar que el gremio reaccione y a través de foros y debates regionales logre, mediante un proceso democrático y quizá con el apoyo de la universidad que indudablemente hace parte del proyecto cultural del Departamento, otorgar la representación y reconocer el liderazgo de sus auténticos gestores, rechazando y denunciando los abusos de quienes han intentado usurpar ese puesto.

El segundo indicador del estado de la cosa musical es el de los eventos con que se estimula la producción, interpretación o difusión de la música. Y debe nombrarse en primera instancia al Festival Folclórico Nacional, en cuyo marco se realizan los concursos de Composición Jorge Villamil Cordovez, de Interpretación Anselmo Durán Plazas, de Rajaleña josé Antonio Cuellar Rumichaca y de Bandas Milciades Chato Durán. Es justo reconocer el nivel de acreditación que estos certámenes han llegado a adquirir. A pesar de la evidente parcialidad de la prensa nacional por el evento paralelo en la ciudad de Ibagué, el nuestro va ganando prestigio por su seriedad y altura. A nivel urbano, el colegio Departamental Femenino ha logrado posicionar su Concurso Intercolegial de Rajaleña, el cual constituye un magnífico escenario para difundir el aire nativo entre jóvenes y niños.

En tercer lugar hay que reseñar el estado de las instituciones encargadas de generar, orientar y dinamizar el desarrollo musical del departamento. El Instituto Huilense de Cultura (hoy Se- 
cretaría de Cultura) no ha podido sustraerse a la crisis que tiene al borde del colapso al gobierno departamental a pesar de que las dos últimas administraciones han tratado de reorganizar, reestructurar y recuperar procesos, las secuelas de los desaciertos y despilfarros de alguna de las anteriores, obligaron a medidas de choque. No es éste el momento, pero indudablemente deben evaluarse los resultados de la gestión de este organismo en los diferentes proyectos culturales que se le han encomendado. Los que hacen relación con la música son la Banda Departamental, las Bandas Municipales y el Conservatorio. Nuestra Banda Departamental ha hecho méritos suficientes para el adjetivo de Sinfónica que se le asigna. A pesar de la incredulidad o de la sonrisa irónica que en escenarios como la televisora nacional suscita este título, nuestra Banda Departamental ha terminado por convencer a propios y extraños del nivel de calidad alcanzado: obras de muchos directores entre los que debe mencionarse al recientemente desaparecido Abel Valderrama Yusti, han encontrado en el trabajo de su actual conductor, Rafael Serrano Barceló, la técnica y la dedicación que la han dotado del estilo y la expresión propia para hacerse acreedora a primeros puestos en competencias de carácter nacional como el reconocido concurso de bandas de la ciudad de Paipa. Las bandas municipales, en cambio, en una decisión muy discutida, fueron entregadas a las alcaldías respectivas, las cuales por un lado no cuentan con la disponibilidad presupuestal y por otro las utilizan para fines personales o electorales. El Conservatorio Departamental de Música, bajo la dirección actual del maestro Juan Javier Polanía ha logrado recuperar el nivel de calidad que le hizo famoso en los tiempos míticos de la dirección del Padre Rosa y ha ido viendo aumentar su demanda entre niños, jóvenes y adultos hasta la cifra de 300 -inscritos a que llegó el año anterior. Para el presente año la Secretaría de Cultura presentará a la Asamblea una propuesta que le dé autonomía presupuestal y asegure su supervivencia. De otra parte, las Casas de la Cultura deberían haber creado las condiciones requeridas para impartir formación musical en cada municipio, pero la aludida situación anómala de los Fondos Mixtos convirtió a estas casas en fantasmas inoperantes.

Dos instituciones han venido a cumplir un papel similar al del Conservatorio en el campo de la formación musical: El Ceinar, experiencia pedagógica musical de iniciativa autóctona y que ha logrado completar uno de los poquísimos bachilleratos artísticos, entre ellos el musical, en el territorio patrio. La ciudadanía le reconoce a Nohora de Chávarro la gestión para dotar la institución de los recursos locativos y técnicos y de las herramientas metodológicas que hicieron a su PEl acreedor de estimulo o premio nacional. La Fundación Batuta por su parte, viene desarrollando un eficaz proceso de formación musical para la estructuración de orquestas sinfónicas juveniles, ofreciendo así una respuesta concreta a los muchos problemas que se derivan para nuestra niñez y adolescencia de la carencia de espacios de formación humana en ámbitos no formales. Iniciativa nacional del gobierno de Gaviria, no contó como era de imaginarse, con el apoyo del gobierno siguiente ni en el orden nacional ni en el del Huila, a pesar de solicitudes y súplicas. Pero gracias al desempeño de alguna cooperativas que la apoyaron y sobre todo de la labor pedagógica propiamente gra- 
tuita de Rafael Serrano, hoy parece ya consolidada, como que los directivos nacionales la consideran de las de mejor calidad y la apoyan con la entrega de instrumentos y la formación de los docentes. Y le toca el turno al Programa de Licenciatura en Música de la Universidad Surcolombiana. Surgido de las antiguas Escuelas Artísticas creadas por el Instituto Huilense de Cultura, fue acogido por la universidad, dentro del convenio suscrito con el Departamento en el que éste se comprometía a apoyar el programa con aporte anual al presupuesto de la Universidad para el pago de docentes y para dotación e inversión, promesa que el gobierno de Losada incumplió, causando el consiguiente perjuicio a las finanzas de nuestra casa de estudios. El Programa ha venido logrando hasta ahora, el objetivo básico de profesionalizar los docentes de música, actualmente en ejercicio en los diferentes centros docentes de primaria, secundaria y media del Departamento y de preparar una nueva generación de profesores que establezca las bases de una etapa de actualización en la formación musical en la región. Ha entregado unos ochenta licenciados en música en su primera etapa y hará otro tanto en los próximos 4 años. Pero por razones estratégicas de supervivencia, se fundirá con los otros dos programas del Departamento de Artes (Visuales y Escénicos) para formar un licenciado en Educación Artística, en aras de poderse acreditar, cumpliendo, los requisitos exigidos por el decreto 272.

Academias de enseñanza musical han hecho su aparición como corolario de la profesionalización de docentes de música, y del ambiente, más imaginario que real, de apoyo a la iniciativa privada que han pregonado los gobiernos neoliberales.

$Y$ es precisamente la educación musical de carácter formal, el indicador que nos retrata el estado actual de la música en nuestra región. Aunque no satisfecha todavía la demanda de licenciados en música, puede sin embargo preverse que la presencia de un buen número de ellos constituya factor decisivo en el mejoramiento de la calidad de la enseñanza de este arte en nuestras instituciones educativas y se manifieste en una nueva actitud de los jóvenes, hacia la música y especialmente hacia la música nuestra. No existen sin embargo, análisis e investigaciones de campo que nos permitan sustentar este aserto. Por lo pronto se nota algún interés por la conformación de agrupaciones autóctonas (rajaleñas, música andina) en los colegios y escuelas a través de la participación en los concursos ya aludidos. Pero la preferencia musical de nuestros jóvenes, obviamente no va en esta dirección. Podría esperarse, con algún fundamento que la familia media (no la de clase alta que tiene otros gustos e intereses, ni la de clase baja que no puede ejercer ninguna labor educativa), como transmisor cultural, influya en el mantenimiento del gusto por lo huilense y lo local: pero surgen, frente a esta hipótesis serias dudas acerca de la conciencia de identidad regional de nuestras gentes como para ejercer esta función, que sí cumplen antioqueños, vallunos cesarences, etc., con sus hijos.

La recuperación histórica de nuestro acervo musical es decisiva. Salvo sin embargo, Los trabajos del maestro Jairo Beltran para la Historia General del Huila y para la página musical que el diario la Nación le encargó durante un 
tiempo o pequeñas publicaciones sobre autores huilenses como la de los alumnos de nuestro Programa de Música, no se ha llenado todavía el vacío en este campo. En el análisis de nuestros aires terrígenas, el trabajo del Padre Rosa, Esencia, presencia y estilo del Rajaleña, ocupa un lugar destacado por el rigor científico y la pertinencia temática, reconocidos por instituciones nacionales como el Instituto Caro y Cuervo o el Patronato Colombiano de Artes y Ciencias. El campo de la teorización sigue también inexplorado: no existe en nuestro medio un trabajo sobre alguna de las dimensiones o elementos esenciales de la música, salvo opúsculos muy puntuales, generalmente destinados a menesteres didácticos, (módulos, apuntes, sinopsis). Al igual que la crítica de obras o espectáculos musicales, nuestra prensa local se abastece de los comentarios de la prensa nacional o de las revistas de opinión.

No podríamos terminar este somero análisis sin hacer referencia a la audiencia, al consumo de los productos musicales en nuestro entorno cultural: y ello nos lleva a la discusión sobre el papel desempeñado por los medios de comunicación, especialmente los radiales y las cadenas de distribución de discos, videos musicales, etc., acusados de mercantilismo por no difundir nuestra música regional y que se defienden aduciendo que ellos venden o difunden lo que la gente solicita, gusta o consume, cerrando un inextricable círculo vicioso que solo se romperá a través de un verdadero propósito de defender y difundir lo nuestro, aunque nadie les exige que lo hagan con exclusividad. $Y$ el otro ineludible debate sobre nuestra música es el de los puristas, aferrados a lo tradicional y los partidarios de la actualización y evolución de nuestros géneros musicales populares y folclóricos. ¿Podrán nuestros bambucos, pasillos y guabinas dar la pelea frente a lá inundación de vallenato, del rock doméstico y el extranjero, de la salsa barata y el merengue intrascendente y repetitivo, si no se viste de nuevas galas sin perder su esencia ni vender su dignidad? ¿Tendría el vallenato la aceptación de nuestra juventud sin el aporte, musicalmente insignificante pero externamente novedoso y llamativo de la mezcla con el rock que le dio el joven Vives? ¿Cantarían y siquiera conocerían nuestros jóvenes el bolero sino fuera por las nuevas versiones en forma de baladas que sus ídolos interpretan de manera diferente a la que aprendimos en la generación anterior? ¿Perdieron o ganaron los valses peruanos y pasillos ecuatorianos que ingresaron al repertorio de las nuevas generaciones a través de la versión melosa de Charlie Zaa? ¿Requieren nuestros aires autóctonos, rajaleña, sanjuanero, etc., un proceso de urbanización y un enriquecimiento melódico, armónico, etc., respetuoso pero artístico e inspirado? El debate es saludable, la reflexión es oportuna.

Finalmente, nos preguntamos por la misión de la Universidad en el campo de la producción, interpretación, difusión actualización de nuestra música, en todos sus géneros y manifestaciones. En primera instancia crea los ámbitos para el cultivo musical por parte de nuestros estudiantes, profesores y en general, de todos los estamentos que conforman su comunidad. En segundo lugar el estudio serio y sistemático que reemplace la aproximación empírica y eso se logra investigando y para investigar hay que leer y para ello disponer de la bibliografía apropiada pero también del contacto con quienes 


\section{5}

PAIDEIA

hacen la sistematización teórica junto con la validación práctica. El aporte específico de la Universidad debe canalizarse en el ámbito de la investigación: es imprescindible partir de datos confiables, de estudios de campo, de recuperaciones históricas, de recopilaciones hechas con la técnica que hoy los medios de comunicación ponen a nuestro alcance. En tercer lugar, abrir espacios de expresión para que nuestros futuros docentes en el campo de la música opinen, planteen hipótesis, generen controversia racional y respetuosamente. $Y$ no en último lugar, recuperar el liderazgo cultural en el campo de la música a través de una organización y representación auténtica que responda a las verdaderas necesidades del desarrollo musical de nuestra región.

llustración: Rubert Dario Conde

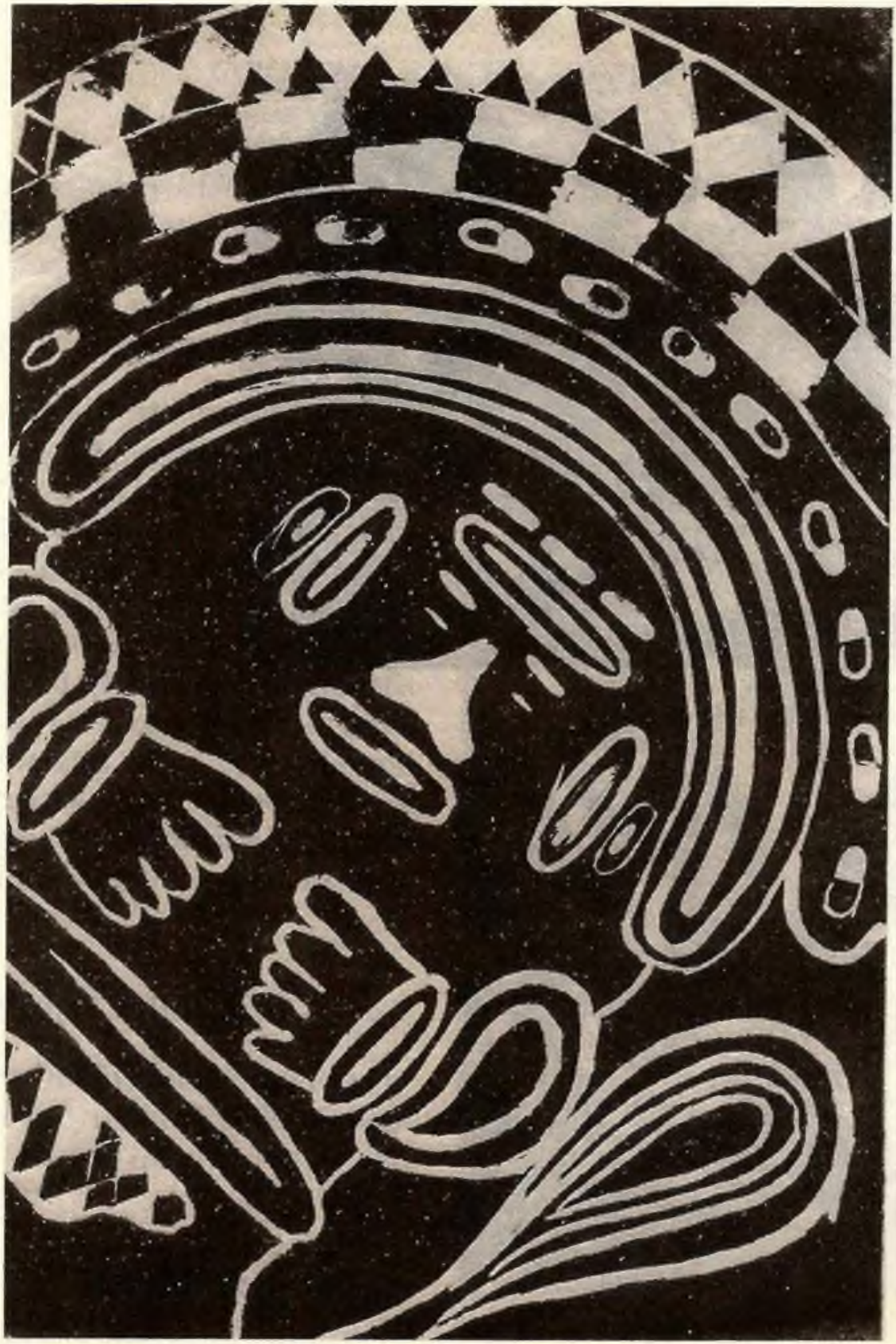




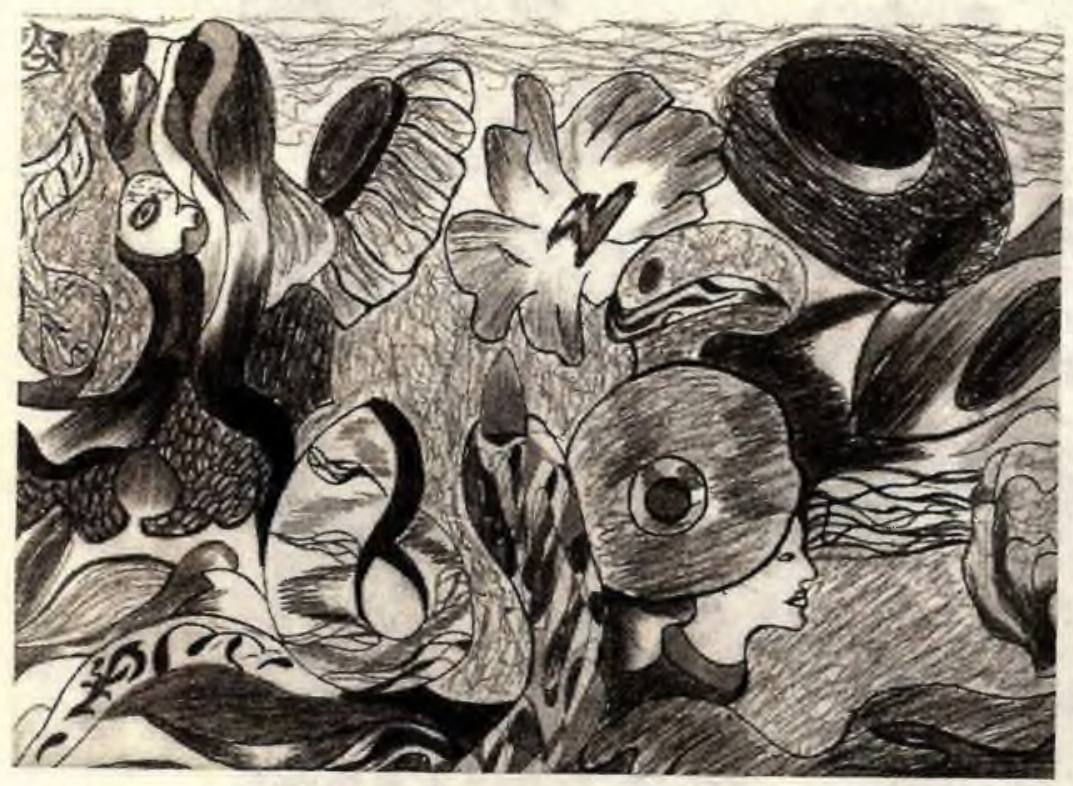

Ilustración: Luz Dary Laso Calderón 